\section{Jupana HORIZON}

PENDIDIKAN

Publish by: Library of STKIP PGRI Sumatera Barat

E-ISSN : 2775-5770

Vol. 1 No. 4 (November 2021) (698-711)

http://ejournal.stkip-pgri-sumbar.ac.id/index.php/horizon

\title{
HUBUNGAN KEPERCAYAAN DIRI SISWA DENGAN PEMAHAMAN KONSEP MATEMATIS SISWA KELAS XI MIA 1 SMAN 3 LUBUKBASUNG KABUPATEN AGAM
}

Vuve Ona Rahma Suci, Melisa, Hamdunah

Program Studi Pendidikan Matematika STKIP PGRI Sumatera Barat Vuveona@gmail.com

Submitted: 07-09-2021, Reviewed: 17-09-2021, Accepted: 10-11-2021

\begin{abstract}
The lack of self-confidence and the ability to understand concepts that are still low from class XI MIA 1 SMAN students are the background of this research. One of the factors that affect students' ability to understand concepts is self-confidence. This study aims to determine the relationship between students' self-confidence and the ability to understand mathematical concepts of students in class XI MIA SMAN 3 Lubuk Basung, Agam Regency. This study uses a quantitative research type with the type of correlational method. According to Creswell (2014), correlational quantitative research is research using statistical methods that measure the influence between two or more variables. The subject of this research is purvosive sampling, which is 11 students from class XI MIA 1 SMAN 3 Lubuk Basung, Agam Regency. The research instrument used is a selfconfidence questionnaire and a test of understanding mathematical concepts. The data analysis technique used is simple linear regression analysis and product moment correlation.Based on the regression coefficient data analysis, the significance level of the questionnaire score is $r=0.662$, because the regression coefficient (b) is positive, there is a positive effect of students' self-confidence on students' understanding of mathematical concepts. So it can be concluded that there is a relationship between students' self-confidence and understanding of mathematical concepts in class XI MIA 1 SMAN 3 Lubuk Basung, Agam Regency.
\end{abstract}

Keywords: Self-Confidence, Ability To Understand Mathematical Concepts, Correlation.

\section{PENDAHULUAN}

Pendidikan merupakan upaya dalam menciptakan proses pembelajaran dan kondisi belajar supaya peserta didik secara aktif menumbuhkan potensi dirinya agar mempunyai intensitas spiritual keagamaan, kecerdasan, kepribadian, serta keterampilan yang dibutuhkannya dan masyarakat. Manusia melalui pendidikan mampu memperluas wawasannya dan memperoleh pengetahuan yang dikembangkan melalui proses belajar dan pembelajaran. Matematika berperan penting dalam 
HORIZON

PENDIDIKAN

JURNAL HORIZON PENDIDIKAN

Publish by: Library of STKIP PGRI Sumatera Barat

E-ISSN : 2775-5770

Vol. 1 No. 4 (November 2021) (698-711)

http://ejournal.stkip-pgri-sumbar.ac.id/index.php/horizon

perkembangan kehidupan, karena dengan pengetahuan matematika dapat membantu memahami berbagai permasalahan sosial maupun ekonomi. Menurut Kline, \& Suherman (2003:17) menyatakan secara umum matematika bukanlah pengetahuan sempurna karena dirinya sendiri, tetapi adanya matematika untuk membantu memahami dan menguasai permasalahan sosial, ekonomi dan alam. Oleh karena itu matematika digunakan untuk menunjang keberhasilan dalam menempuh jenjang pendidikan dasar, menengah hingga perguruan tinggi.

Sejalan dengan uraian di atas pembelajaran matematika merupakan upaya guru mendorong siswa mengonstruksi pemahamannnya tentang matematika. Siswa dapat membangun, menginterprestasi dan mengaplikasikan pemahamannya. Kelengkapan sarana dan prasarana sekolah juga dapat membantu guru dalam proses pembelajaran untuk meningkatkan pemahaman siswa. (National Council of Teachers of Mathematics, 2000:16) pembelajaran matematika merupakan pembelajaran yang memerlukan pemahaman dan pengetahuan serta apa yang dibutuhkan untuk belajar, kemudian untuk memenuhi kebutuhan agar dapat belajar dengan baik.

Berdasarkan hasil wawancara yang dilakukan dengan guru matematika kelas X MIA SMAN 3 Lubuk Basung diperoleh informasi bahwa masih banyak siswa yang belum mencapai nilai ketuntasan minimum (KKM). Guru sudah berusaha supaya siswa mampu tampil percaya diri dan memahami materi selama proses belajar mengajar. Namun, hanya beberapa siswa yang merespon pertanyaan dan penjelasan yang di sampaikan guru. selama proses pembelajaran berlangsung sebagian siswa belum memiliki rasa percaya diri dalam mengerjakan tugas sehingga siswa cenderung meminta bantuan teman dalam menyelesaikan tugasnya. Saat guru memberi latihan, masih banyak siswa beranggapan bahwa soal yang diberikan guru sulit dikerjakan. Hal ini membuat siswa mudah putus asa dalam mengerjakan latihan yang diberikan guru. Begitu juga dengan pemahaman konsep matematis siswa 


\section{Jupana HORIZON} PENDIDIKAN

JURNAL HORIZON PENDIDIKAN

Publish by: Library of STKIP PGRI Sumatera Barat

E-ISSN : 2775-5770

Vol. 1 No. 4 (November 2021) (698-711)

http://ejournal.stkip-pgri-sumbar.ac.id/index.php/horizon

ketika siswa dihadapkan pada soal matematika, paling banyak siswa mengalami kesulitan dalam hal mengklasifikasi permasalahan dari soal-soal, siswa mengalami kesulitan dalam hal mengaplikasikan konsep pada masalah dan sebagian siswa yang mampu menyatakan ulang sebuah konsep mereka tidak mampu mengembangkan syarat suatu konsep dalam perhitungan hingga penarikan kesimpulan sehingga hasil belajar yang didapatkan siswa rendah. Menurut Dediknas dalam Shadiq, (2009:13) menyatakan bahwa "pemahaman konsep merupakan kompetensi yang ditunjukan siswa dalam memahami konsep dan prosedur (algoritma) secara luwes, akurat, efisien, dan tepat". Menurut Kesumawarti, (2016:13) menyatakan bahwa "siswa dapat dikatakan memahami sebuah konsep apabila siswa mampu mendefenisikan suatu konsep, mengidentifikasikan dan memberikan contoh non contoh dari konsep, mengembangkan kemampuan koneksi matematika, memahami berbagai macam ide-ide matematika yang saling berkaitan satu sama lain sehingga membangun pemahaman menyeluruh, serta dapat menggunakan konteks matematika diluar matematika". Berdasarkan yang telah dipaparkan tentang kepercayaan diri siswa dan kemampuan pemahaman konsep matematis di atas menunjukkan bahwa kepercayaan diri dan kemampuan pemahaman konsep matematis sangat penting dan terdapat hubungan untuk kelancaran dalam proses pembelajaran serta akan berpengaruh terhadap hasil belajar yang diperoleh siswa Anisyak \& Nur (2019 : 189). Sejalan dengan itu, hasil penelitian yang telah dilakukan Menurut Safitri, (2015) menyatakan rasa percaya diri berhubngan dengan prestasi belajarnya. Hal ini dibuktikan dari hasil data yang menghasilkan koefisien relasi sebesar 0,460 yang menunjukan adanya korelasi positif yang sedang antara rasa percaya diri dengan hasil belajar matematika siswa. Penelitian yang dilakukan menurut Wahyuni, T (2019) menunjukan bahwa terdapat pengaruh siswa yang yang memiliki kepercayaan diri tinggi, sedang dan rendah terhadap pemahaman konsep 
HORIZON

PENDIDIKAN
JURNAL HORIZON PENDIDIKAN

Publish by: Library of STKIP PGRI Sumatera Barat

E-ISSN : 2775-5770

Vol. 1 No. 4 (November 2021) (698-711)

http://ejournal.stkip-pgri-sumbar.ac.id/index.php/horizon matematis, dimana pemahaman konsep matematis siswa yang mempunyai kepercayaan diri lebih baik dari pada siswa yang mempunyai kepercayaan diri sedang dan kepercayaan diri rendah.

Berdasarkan latar belakang masalah di atas, peneliti melakukan penelitian yang berjudul "Hubungan

Kepercayaan Diri siswa dengan Pemahaman Konsep Matematis Siswa Kelas XI MIA 1 SMAN 3 Lubuk Basung Kabupaten Agam”.

\section{METODE PENELITIAN}

Penelitian ini merupakan penelitian kuantitatif dengan jenis metode korelasional. Menurut Krewell (2014), penelitian kuantitatif korelasional adalah penelitian dengan menggunakan motode statistik yang mengukur pengaruh antara dua variabel atau lebih. Variabel yang digunakan dalam penelitian korelasi minimal dua variabel yaitu variabel $\mathrm{X}$ dan variabel $Y$. Hal ini sejalan dengan pendapat dari Sukardi (2009: 166) penelitian korelasi adalah suatu penelitian yang melibatkan tindakan pengumpulan data guna menentukan, apakah ada hubungan dan tingkat hubungan antara dua variabel atau lebih.

Subjek penelitian dipilih secara purposive sampling. Teknik purposive sampling merupakan teknik pengumpulan sampel dengan pertimbangan tertentu menurut Sugiyono (2013: 85). Kelas subjek yang dipilih adalah kelas XI MIA 1 dengan sampel 11 Orang siswa. Berdasarkan saran dari guru mata pelajaran matematika SMAN 3 Lubuk Basung kelas XI MIA 1 merupakan kelas yang memiliki kepercayaan diri dan pemahaman konsep matemais yang rendah. Oleh karena itu, kelas tersebut akan diberikan angket untuk melihat kepercayaan diri siswa dan soal tes pemahaman konsep siswa untuk mengukur pemahaman konsep matematis siswa.

Menurut (Arikunto, 2010: 203) "instrumen peneliti adalah alat atau fasilitas yang digunakan oleh peneliti dalam mengumpulkan data agar pekerjaannya lebih mudah dan hasilnya lebih baik, dalam arti lebih cermat, lengkap dan sistematis sehingga lebih mudah diolah". 
HORIZON

PENDIDIKAN
JURNAL HORIZON PENDIDIKAN

Publish by: Library of STKIP PGRI Sumatera Barat

E-ISSN : 2775-5770

Vol. 1 No. 4 (November 2021) (698-711)

http://ejournal.stkip-pgri-sumbar.ac.id/index.php/horizon
Penelitian ini menggunakan dua jenis instrumen penelitian yaitu tes dan angket. Instrumen tes digunakan untuk mengukur pemahaman konsep matematis siswa, dan instrumen angket digunakan untuk mengukur tingkat kepercayaan diri siswa. Maka instrumen yang digunakan adalah sebagai berikut:

\section{Angket Kepercayaan Diri}

Angket termasuk alat untuk mengumpulkan dan mencatat data atau informasi. Menurut Riduwan (2010: 71) angket adalah daftar pertanyaan yang diberikan kepada orang lain bersedia memberikan respon (responden) sesuai dengan permintaan pengguna.

Angket yang digunakan pada penelitian ini adalah angket baku kepercayaan diri menurut Saepullah dalam Hendriana dkk. Tujuan angket kepercayaa diri ini adalah untuk mengetahui kepercayaan diri siswa. Angket kepercayaan diri ini telah disusun berdasarkan indikatorindikator kepercayaan diri. Pernyataan terdiri dari pernyataan positif dan negatif. Angket yang digunakan adalah angket baku yang bersifat tertutup yang dimodifikasi sesuai dengan pembelajaran sekarang. Angket kepercayaan diri divalidasi oleh dosen pembimbing. Hasil validasi oleh dosen pembimbing angket layak diberikan dengan sedikit perbaikan angket dimodifikasi sesuai dengan kondisi pembelajaran dan karakter siswa.

2. Tes Pemahaman Konsep Matematis

Menurut Arikunto(2010: 266)tes merupakan instrumen yang digunakan untuk mengukur ada atau tidaknya serta besarnya kemampuan objek yang diteliti”. Tes tertulis yang diberikan berupa soal-soal dalam bentuk esai berdasarkan pokok bahasan materi. Tes berfungsi untuk mengukur kemampuan pemahaman konsep siswa dalam menjawab persoalan matematika. Pada penelitian inisoal dalam bentuk uraian (essay) berisi materi yang memuat indikator pemahaman konsep.

\section{HASIL DAN PEMBAHASAN}

A. Deskripsi Data

Penelitian ini dilakukan pada siswa yang telah mempelajari materi limit fungsi di Kelas XI MIA 1 SMAN 3 Lubuk Basung Kabupaten 


\section{HORIZON}

PENDIDIKAN
JURNAL HORIZON PENDIDIKAN

Publish by: Library of STKIP PGRI Sumatera Barat

E-ISSN : 2775-5770

Vol. 1 No. 4 (November 2021) (698-711)

http://ejournal.stkip-pgri-sumbar.ac.id/index.php/horizon
Agam. Subjek penelitian adalah siswa kelas XI MIA 1 tahun ajaran 2021/2022 Semester Genap sebanyak 29 orang siswa. Penelitian ini bertujuan untuk mengetahui bagaimana hubungan kepercayaan diri siswa dengan pemahaman konsep matematis siswa XI MIA 1 SMAN 3 Lubuk Basung.

Penelitian ini menggunakan penelitian kuantitatif dengan jenis metode korelasional dimana penelitian kuantitatif korelasional merupakan penelitian dengan menggunakan metode statistik yang mengukur pengaruh antara dua variabel atau lebih. matematis siswa diperoleh melalui angket kepercayaan diri dan tes kemampuan pemahaman konsep.jenis Data yang diperoleh kemudian dianalisis untuk menunjukan hubungan kepercayaan diri siswa dengan kemampuan pemahaman konsep matematis siswa.

1. Angket Kepercayaan diri siswa

Kepercayaan diri siswa dapat dilihat dari angket yang dibagikan pada kelas penelitian dengan jumlah responden $11 \quad$ siswa.Tingkat kepercayaan diri dapat dilihat dari persentase perindikator yang disajikan pada Table 8 .

Data kepercayaan diri siswa dan kemampuan pemahaman konsep

\begin{tabular}{clc}
\hline \multicolumn{3}{l}{ Tabel 10. Persentase Kepercayaan Diri Perindikator } \\
\hline NO & \multicolumn{1}{l}{ Indikator } & Skor (\%) perindikator \\
\hline 1 & $\begin{array}{l}\text { Berpendapat atau melakukan kegiatan } \\
\text { tanpa ragu-ragu }\end{array}$ & 77,84 \\
2 & $\begin{array}{l}\text { Mampu membuat keputusan dengan } \\
\text { cepat }\end{array}$ & 74,24 \\
3 & Tidak mudah putus asa & 74,24 \\
4 & Tidak canggung dalam bertindak & 79,54 \\
5 & Berani presentasi didepan kelas & 72,15
\end{tabular}




\section{( \\ HORIZON}

PENDIDIKAN
JURNAL HORIZON PENDIDIKAN

Publish by: Library of STKIP PGRI Sumatera Barat

E-ISSN : 2775-5770

Vol. 1 No. 4 (November 2021) (698-711)

http://ejournal.stkip-pgri-sumbar.ac.id/index.php/horizon

6 Berani berpendapat,bertanya,atau

menjawab pertanyaan $\quad 78,78$

Rata-rata

76,131

Berdasarkan Table 10 diatas terlihat

bahwa persentase kepercayaan diri

\begin{tabular}{ccccc} 
Kelas & $\begin{array}{c}\text { Jumlah } \\
\text { Siswa }\end{array}$ & $\underline{\boldsymbol{x}}$ & \multicolumn{2}{c}{$\boldsymbol{x}_{\max } \boldsymbol{x}_{\min }$} \\
\hline $\mathrm{XI}$ & 11 & 8.045 & 10 & 41
\end{tabular}

perindikator berada antara 72 sampai 79,54\%.

2. Soal Tes Kemampuan

Pemahaman Konsep

Pelaksanaan tes kemampuan

pemahaman konsep dillakukan pada

kelas penelitian XI MIA 1sebanyak

11 orang siswa. Setelah dilaksanakan

tes kemampuan pemahaman konsep

diperoleh data tentang hasil belajar matematika siswa. Berdasarkan perhitungan didapat nilai rata-rata $(\underline{x})$, skor tertinggi $\left(x_{\max }\right)$, skor terendah $\left(x_{\min }\right)$, tes akhir pada kelas eksperimen sesuai dengan Tabel 9.

Tabel 11. kemampuan pemahaman konsep . Perhitungan Rata-rata $\quad(\underline{x}), \quad$ Skor Tertinggi $\left(x_{\max }\right)$, skor Terendah $\left(x_{\min }\right)$ Kelas Sampel

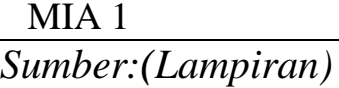

Pada Table 11 dapat dilihat bahwa tes kemampuan pemahaman konsep dapat diperoleh nilai tertingginya adalah 100 dan nilai terendah 41.

3. Hasil Uji Hipotesis Korelasi Hipotesis Kepercayaan Diri Siswa dengan Pemahaman Konsep Matematis Siswa

Korelasi antara kepercayaan diri siswa dengan pemahaman konsep matematis siswa dapat diketahui setelah dilakukan uji hipotesis denan bantuan SPSS. Dalam penelitian ini, data akan dianalisis menggunakan metode korelasi dengan menggunakan bantuan SPSS 16. Dari hasil analisis data maka diperoleh hasil sebagai berikut :

\section{Correlations}

\begin{tabular}{|c|c|c|c|}
\hline & & $\begin{array}{c}\text { Kepercayaan } \\
\text { Diri }\end{array}$ & $\begin{array}{c}\text { Pemahaman } \\
\text { Konsep } \\
\text { Matematis }\end{array}$ \\
\hline Kepercayaan Diri & $\begin{array}{l}\text { Pearson Correlation } \\
\text { Sig. (2-tailed) } \\
\mathbb{N}\end{array}$ & $\begin{array}{r}1 \\
11\end{array}$ & $\begin{array}{r}.662^{\prime} \\
.027 \\
11\end{array}$ \\
\hline $\begin{array}{l}\text { Pemahaman Konsep } \\
\text { Matematis }\end{array}$ & $\begin{array}{l}\text { Pearson Correlation } \\
\text { Sig. (2-tailed) } \\
\mathbb{N}\end{array}$ & $\begin{array}{r}.662^{\prime} \\
.027 \\
11\end{array}$ & $\begin{array}{r}1 \\
11 \\
\end{array}$ \\
\hline
\end{tabular}

*. Correlation is significant at the 0.05 level (2-tailed). 
Publish by: Library of STKIP PGRI Sumatera Barat

E-ISSN : 2775-5770

Vol. 1 No. 4 (November 2021) (698-711)

http://ejournal.stkip-pgri-sumbar.ac.id/index.php/horizon

705 | Vuve Ona Rahma Suci, Melisa, Hamdunah 1 /JHP, Vol. 1 No. 4, 2021 


\section{mane \\ HORIZON}

PENDIDIKAN
JURNAL HORIZON PENDIDIKAN

Publish by: Library of STKIP PGRI Sumatera Barat

E-ISSN : 2775-5770

Vol. 1 No. 4 (November 2021) (698-711)

http://ejournal.stkip-pgri-sumbar.ac.id/index.php/horizon

Tabel 12. Perincian Hasil dianalisis untuk angket kepercayaan Kepercayaan Diri Siswa dengan Kemampuan Pemahaman Konsep Matematis Siswa

Sig. Keteranga Kesimpula

\begin{tabular}{cccc} 
& & $\mathrm{n}$ & $\mathrm{n}$ \\
\hline 0,66 & 0,02 & Sig. 0,05 & Signifikan
\end{tabular}

27

Berdasarkan hasil korelasi

analisis uji korelasi antara kepercayaan diri siswa dengan pemahaman konsep matematis siswa kelas XI MIA 1 SMAN 3 Lubuk Basung, menunjukan bahwa koefisien korelasi kepercayaan diri siswa dengan pemahaman konsep matematis siswa adalah sebesar 0,662. Maka kepercayaan diri siswa dengan pemahaman konsep matematis siswa memiliki korelasi dengan menunjukan tingkat hubungan korelasi dan bentuk hubungannya positif. Karena nilai $r=$ 0,662. Adapun nilai signifikansi adalah $0,027: 2=0,01$. Karena penelitian dua arah yang digunakan pada penelitian ini, maka nilai sig. 2tailed harus dibagi 2.

B. Analisis Data

1. Angket Kepercayaan Diri Siswa Kepercayaan diri siswa kelas XI MIA 1SMAN 3 Lubuk Basungakan diri siswa dengan menentukan jumlah skor kemudian dibagi dengan jumlah skor maksimum dan dikalikan dengan $100 \%$ untuk mendapatkan persentase skor kemandirian belajar dapat dirumuskan:

$\frac{\text { jumlah skor yang diperoleh }}{\text { skor maksimum }} \times 100 \%$

Skor $(\mathrm{s})=$ Skor angket kepercayaan diri siswa yang diberikan dapat dilihat pada lampiran. Berdasarkan rekapitulasi skor angket kepercayaan diri yang diberikan kepada siswa, diperoleh hasil rata-ratanya adalah 7,70 .

Angket kepercayaan diri siswa diberikan langsung kedalam kelas XI MIA SMAN 3 Lubuk Basung pada saat jam pembelajaran matematika wajib bersamaan dengan tes kemampuan pemahaman konsep. Angket ini diberikan kepada seluruh siswa yang ada pada kelas sampel yang beranggotakan 11 orang siswa. Angket ini menggunakan 6 indikator yaitu: (a) berpendapat atau melakukan kegiatan tanpa ragu-ragu, 


\section{JURNAL \\ HORIZON}

PENDIDIKAN

JURNAL HORIZON PENDIDIKAN

Publish by: Library of STKIP PGRI Sumatera Barat

E-ISSN : 2775-5770

Vol. 1 No. 4 (November 2021) (698-711)

http://ejournal.stkip-pgri-sumbar.ac.id/index.php/horizon

(b) mampu membuat keputusan dengan cepat, (c) tidak mudah putus asa, (d) tidak canggung dalam bertindak, (e) berani presentasi didepan kelas, (f) berani berpendapat, bertanya atau menjawab pertanyaan. Berikut persentase skor kepercayaan diri siswa dilihat dari Gambar 2.

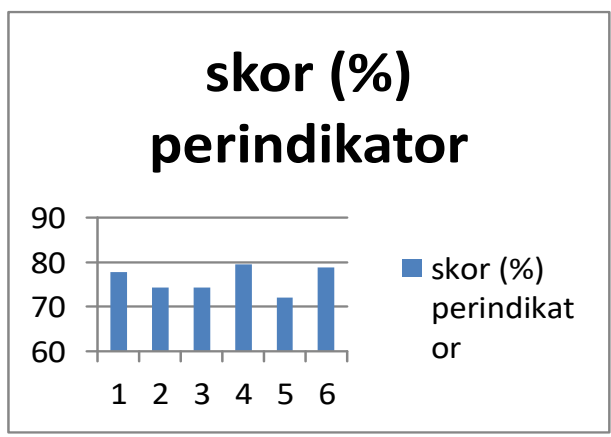

Gambar 2. Persentase Skor Angket Kepercayaan Diri Siswa

Gambar 2. Terlihat bahwa ratarata skor kepercaaan diri siswa berdasarkan indicator berada diatas $70 \%$, ini menunjukkan persentase kepercayaan diri perindikator.

Berdasarkan hasil angket yang diperoleh terlihat adanya hubungan kepercayaan diri dengan kemampuan pemahaman konsep. Dilihat dari analisis perindikator yang pertama berpendapat atau melakukan kegiatan tanpa ragu-ragu. Hal ini ditunjukkan bahwa siswa yakin dapat menyelesaikan soal yang sulit sekalipun, dan ketika sedang berdiskusi siswa akan mengeuarkan ide dan gagasan yang dimiliki, disaat siswa dihadapkan dengan pilihan siswa yakin terhadap semua keputusan yang diambil.

Siswa mampu membuat keputusan dengan cepat. Hal ini terlihat bahwa siswa bertindak sesuai dengan pilihan ketika siswa dihadapkan dengan suatu permasalahan dalam pembelajaran matematika siswa mampu mengambil keputusan tanpa berpikir panjang dan hanya melibatkan diri sendiri tanpa bantuan orang lain. sedangkan pada indicator tidak mudah putus asa. Hal ini dilihat dari siswa tidak mudah menyerah dalam menghadapi persoalan dimana didalam pembelajaran matematika siswa selalu mencoba hal yang baru agar soal yang sulit sekalipun dapat terpecahkan dan dikerjakan dengan sungguh-sungguh, dan bertanggung jawab terhadap apa yang telah dilakukan. 


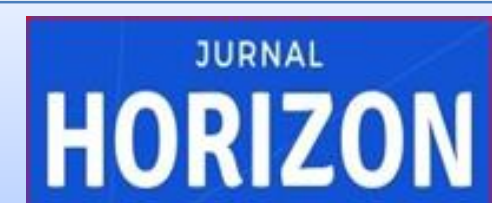

PENDIDIKAN

\section{JURNAL HORIZON PENDIDIKAN}

Publish by: Library of STKIP PGRI Sumatera Barat

E-ISSN : 2775-5770

Vol. 1 No. 4 (November 2021) (698-711)

http://ejournal.stkip-pgri-sumbar.ac.id/index.php/horizon

2. Hasil Uji Hipotesis Korelasi Kepercayaan Diri dengan Pemahaman Konsep Matematis Siswa

Hipotesis dalam penelitian ini adalalah terdapat hubungan positif antara kepercayaan diri siswa dengan matematis di kelas XI MIA SMAN 3 Lubuk Basung.Berdasarkan data yang diperoleh dari skor angket dan skor tes. Analisis yang digunakan adalah analisis korelasional pada table 8 .

kemampuan pemahaman konsep

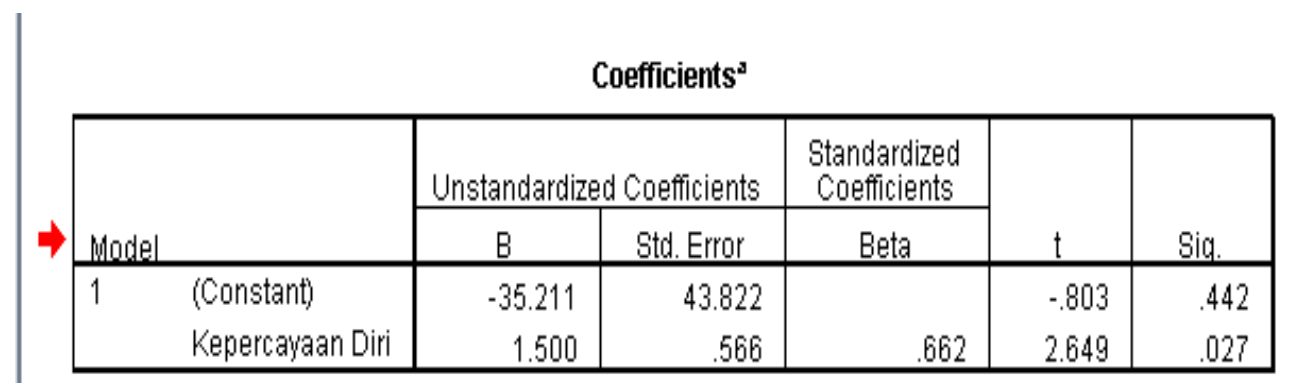

a. Dependent Variable: Pemahaman Konsep Matematis

Table 13. Hasil Regresi Linear Sederhana
Variabel terikat
Variabel regresi
Koefisien regresi
$\mathrm{T}$
Sig

Konstanta

$-35.221$

Tes akhir (Y)

Skor angket (X)

(Sumber : Lampiran VIII Hal ) 


\section{subat HORIZON} PENDIDIKAN
JURNAL HORIZON PENDIDIKAN

Publish by: Library of STKIP PGRI Sumatera Barat

E-ISSN : 2775-5770

Vol. 1 No. 4 (November 2021) (698-711)

http://ejournal.stkip-pgri-sumbar.ac.id/index.php/horizon
Berdasarkan Table 13. Skor Angket (X) dan Tes Kemampuan Pemahaman Konsep (Y) dapat dinyatakan persamaan regresi linear sederhana adalah:

$Y=-a+b X$

$Y=-35.221+1,5 X$

Persamaan regresi linear sederhana diatas dapat diartikan bahwa nilai koefisien regresi skor angker (b) adalah 1,5 dengan tingkat signifikan sebesar 0,27 karena koefisien regresi (b) bernilai positif maka ada pengaruh positif dari $\mathrm{X}$ terhadap Y. Artinya semakin besar X Semakin besar pula $\mathrm{Y}$ secara ratarata. Hal ini dapat dilihat pada gambar 3 dibawah ini .

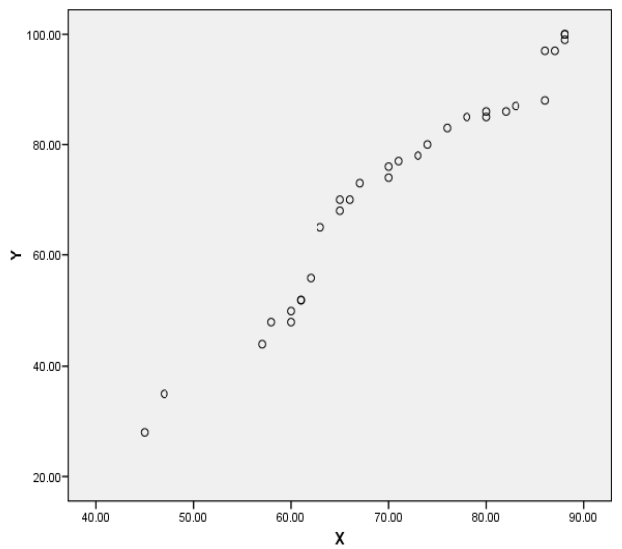

Gambar 5. Grafik hasil analisis Regresi

Keterangan :

$\mathrm{X}=$ Kepercayaan diri siswa

$\mathrm{Y}=$ kemampuan pemahaman konsep
Berdasarkan Gambar 3, terlihat bahwa $b>0$ sehingga grafik garis naik. Akibatnya, setiap kenaikan satu satuan dalam $\mathrm{X}$ akan memberi kenaikan positif sebesar $b$ pada $\mathrm{Y}$.

Berdasarkan analisis nilai kolerasi pearson diperoleh nilai koefisien korelasi $\mathrm{r}=0,662$ yang berarti bahwa $\mathrm{r}$ mendekati 1 , maka hubungan linear antara X dan Y kuat. Nilai $r$ yang positif menunjukan bahwa adanya hubungan linear positif antara $\mathrm{X}$ dan $\mathrm{Y}$, dalam arti semakin besar X semakin besar pula Y. (Lampiran IX).

\section{KESIMPULAN}

Berdasarkan hasil penelitian dan analisis data yang telah dilakukan di SMAN 3 Lubuk Basung Kabupaten Agam ditemukan hasil penelitian berupa, kepercayaan diri siswa yang didapat dari angket yang diberikan kepada siswa yang berupa pernyataan dengan nilai maksimumnya adalah 85 dan minimumnya adalah 66. Dari data tersebut didapat nilai rata-ratanya sebesar 7,7. Pemahaman konsep matematis siswa yang didapat dari 
HORIZON

PENDIDIKAN

JURNAL HORIZON PENDIDIKAN

Publish by: Library of STKIP PGRI Sumatera Barat

E-ISSN : 2775-5770

Vol. 1 No. 4 (November 2021) (698-711)

http://ejournal.stkip-pgri-sumbar.ac.id/index.php/horizon

soal yang diberikan kepada siswa yang berupa soal pemahaman konsep matematis siwa dengan nilai maksimumnya 100 dan minimumnya adalah 41. Berdasarkan hasil data yang dilakukan dapat diketahui bahwa terdapat pengaruh yang signifikan antara variable kepercayaan diri siswa terhadap pemahaman konsep matematis siswa kelas XI MIA 1 SMAN 3 Lubuk Basung Kabupaten Agam. Kepercayaan diri yang baik akan meningkatkan kemampuan pemahaman konsep matematis siswa. Sebaliknya jika kepercayaan diri siswa kurang baik akan membuat siswa kurang dalam pemahaman konsepnya. Hasil penelitian menunjukan bahwa kepercayaan diri memiliki pengaruh terhadap kemampuan pemahaman konsep matematis siswa kelas XI MIA 1 SMAN 3 Lubuk Basung. Hasil penelitian ini sejalan dengan Lailatul Lutfiah (2006:80), yaitu bahwa kepercayaan diri siswa berpengaruh terhadap kemampuan pemahaman konsep matematis.

Situasi pembelajaran berkaitan dengan relasi guru dengan siswayang harus

diperhatikan guru.pembelajaran pada hakikatnya merupakan kegiatan belajar mengajar antara guru dan siswa, maka interaksi antara keduanya harus terjalin dengan baik dan guru terbuka dengan siswa. Guru tidak boleh beranggaapan kalu dirinya orang yang pandai dan tidak bisa menerima tanggapan dari siapapun. Sebaliknya guru harus mampu melayani siswa dengan sikap terbuka agar termotivasi siswa untuk belajar dengan baik dengan pemahaman konsep matematis pada siswa meningkat. Selain relasi guru dengan siswa, didalam kepercayaan diri siswa terdapat interaksi yang memungkinkan anak untuk dapat meningkatkan kemampuan pemahaman konsepnya. Hasil penelitian uji instrument penelitian yaitu uji validitas dan uji rehabilitas.Dari hasil uji validitas terdapat beberapa butir instrumen dari masing-masing variabel yang tidak valid, namun ada pula butir instrumen yang dinyatakan valid dengan menggunakan validitas isi dan validitas konstruk. Untuk jumlah responden yang diuji adalah11 
HORIZON

PENDIDIKAN
JURNAL HORIZON PENDIDIKAN

Publish by: Library of STKIP PGRI Sumatera Barat

E-ISSN : 2775-5770

Vol. 1 No. 4 (November 2021) (698-711)

http://ejournal.stkip-pgri-sumbar.ac.id/index.php/horizon responden didapatkan $r$ tabel sebesar

0,662 dengan taraf signifikan

5\%.Dari intrumen untuk angket

variable kepercayaan dirisiswa

didapatkan 20 pernyataan dari 20

pertanyaan, sedangkan untuk

variabel pemahaman konsep

matematis didapatkan 5 pernyataan

dari 5 pertanyaan, artinya untuk

kepercayaan diri siswa dan

pemahaman konsep matematis siswa semua valid.

Berdasarkan hasil analisis regresi sederhana memperoleh nilai untuk pengujiankoefisien regresi skor angket (b) adalah 1,5 dengan tingkat signifikan sebesar 0,27 karena koefisien regresi (b) bernilai positif maka terdapat pengaruh positif dari $\mathrm{X}$ terhadap $\mathrm{Y}$. artinya semangkin besar tingkat kepercayaan diri siswa (X) semangkin besar pemahaman konsep matematis siswa (Y) secara rata-rata.

Berdasarkan analisis korelasi person diperoleh nilai koefisien korelasi $\mathrm{r}=0,662$ yang berarti bahwa r mendekati 1, maka hubungan linear antara $\mathrm{X}$ dan $\mathrm{Y}$ positif. Nilai $\mathrm{r}$ yang positif menunjukan bahwa adanyahubungan linear positif antara
$X$ dan $Y$, dalam arti semangkin besar $\mathrm{X}$ semangkin besar pula Y. Sejalan dengan. Hasil yang diperoleh sesuai dengan teori yang dikemukakan oleh Ramdan Veralita, Rohaeti \& Purwasih 2008) kepercayaan diri merupakan salah satu faktor yang berpengaruh terhadap kemampuan matematis siswa dalam mencapai tujuan hasil belajar yang diharapkan. Sejalan dengan pendapat Lauster ( Pritama,2015:2) yang menyatakan bahwa "percaya diri mempengaruhi sikap hati-hati, tidak ketergantungan, toleransi dan cita-cita” kepercayaan diri mempengaruhi banyak hal yang mendasar pada kepribadian seseorang. Seseorang yang memiliki rasa percaya diri akan berhati-hati dalam bertindak dan mengambil keputusan. Keyakinan terhadap kemampuan diri akan menimbulkan rasa kemandirian dan tidak bergantungan terhadap orang lain juga menjadikan seseorang menjadi egois serta lebih toleran. Cita-cita bagi orang yang memiliki rasa percaya diri juga tergolong normal karena tidak perlu bagi dirinya untuk menutupi ketidak percayaan dirinya dengan cita-cita yang berlebihan. 


\section{Jubat HORIZON} PENDIDIKAN
JURNAL HORIZON PENDIDIKAN

Publish by: Library of STKIP PGRI Sumatera Barat

E-ISSN : 2775-5770

Vol. 1 No. 4 (November 2021) (698-711)

http://ejournal.stkip-pgri-sumbar.ac.id/index.php/horizon
Pada penelitian ini hubungan kepercayaan diri dengan pemahaman konsep matematis siswa kelas XI MIA1 SMAN 3 Lubuk Basung Kabupaten Agam dikategorikan kuat.

\section{DAFTAR PUSTAKA}

Ariani, Suci, Yusuf Hartono, and Cecil Hiltrimartin. 2017. "Kemampuan Pemecahan Masalah Matematika Siswa Pada Pembelajaran Matematika Menggunakan Strategi Abduktif-Deduktif Di SMA Negeri IIndralaya Utara." jurnal elemen 3(1): 25-34.

Arikunto. 2010. "Analisis Pemahaman Konsep Siswa Materi Manusia Dan Lingkungan Dikaitkan Faktor Belajar Siswa Di Kelas." : 30.

Kesumawarti, ddk. 2016. "Pengaruh Desentralisasi Pendidikan Dasar Terhadap Kualitas Pendidikan Di Kabupaten Jembrana Provinsi Bali.": 13.

Kline, \& Suherman. 2003. "Pengembagan Petunjuk Pratikum Biologi Pada Materi Jamur Dengan Pola Pemberdayaan Bepikir Melalui Pertanyaan (Studi Kasus X.3 SMA Muhamadiyah 1 Metro Tahun Pelajaran 2013/2014)." BIOEDUKASI 7(1): 17.

National Council of Teachers of Mathematics. 2000. Principles and Standards for School Mathematics.
Riduwan. "Analisis Pemahaman Konsep Siswa Materi Archaebacteria Dan Eubacteria." 2010: 89.

Safitri. 2015. "Volume 23 Nomor 5 Maret 2012 MANAJEMEN PENDIDIKAN Diterbitkan Pertama Kali Tahun 1988 Oleh Jurusan Administrasi Pendidikan Dengan Nama KELOLA ."

Shadiq, Dediknas dalam. 2009 "Manajemen Kurikulum Sebagai Pengembangan Tujuan Pendidikan.": 13.

Sugiyono. 2013. "Analisis Pemahaman Konsep Siswa Materi Manusia Dan Lingkungan Dikaitkan Faktor Belajar Siswa Di Kelas.” : 85.

Wahyuni, Tri. 2019. Teori Belajar Pembelajaran Di Sekolah Dasar. PT Fajar Interpratama Mandiri. 